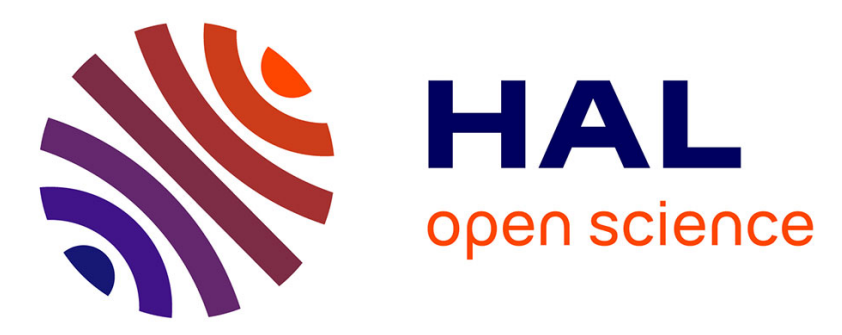

\title{
Beam self-trapping in pyroelectric photorefractive crystals
}

\author{
J. Safioui, F. Devaux, K. Phan Huy, M. Chauvet
}

\section{To cite this version:}

J. Safioui, F. Devaux, K. Phan Huy, M. Chauvet. Beam self-trapping in pyroelectric photorefractive crystals. CLEO 2009 Conference on Lasers and Electro-Optics Europe, Jun 2009, Munich, Germany. 10.1109/CLEOE-EQEC.2009.5192180 . hal-00472318

\section{HAL Id: hal-00472318 \\ https://hal.science/hal-00472318}

Submitted on 15 Apr 2021

HAL is a multi-disciplinary open access archive for the deposit and dissemination of scientific research documents, whether they are published or not. The documents may come from teaching and research institutions in France or abroad, or from public or private research centers.
L'archive ouverte pluridisciplinaire HAL, est destinée au dépôt et à la diffusion de documents scientifiques de niveau recherche, publiés ou non, émanant des établissements d'enseignement et de recherche français ou étrangers, des laboratoires publics ou privés. 


\title{
Beam self-trapping in pyroelectric photorefractive crystals
}

\author{
J. Safioui, F. Devaux, K. P. Huy, M. Chauvet \\ Département d'Optique, Institut FEMTO-ST, UMR CNRS 6174, Université de Franche-Comté
}

16, route de Gray, 25030 Besançon cedex, France

While most photorefractive (PR) beam self-trapping configurations require application of a high external voltage [1] we instead propose to use PR pyroelectric medium to efficiently trap beams by simple temperature control. This new concept is based on uniform temperature change of a pyroelectric PR crystal which creates an internal electric field that is screened under a local illumination by nonlinear photorefractive effect. Experimental demonstration is performed in the widely available photonic material Lithium niobate $\left(\mathrm{LiNbO}_{3}\right)$.

A pyroelectric solid exhibits a change in spontaneous polarization $\Delta P$ under a temperature variation $\Delta T$ given by $\Delta P=\mathrm{p} \Delta T$ where $\mathrm{p}$ is pyroelectric coefficient of the medium. This polarization change gives an internal electric field $E$ can then be calculated through the relation $E=-1 /\left(\varepsilon_{0} \varepsilon\right) p \Delta T$ where $\varepsilon$ is the medium dielectric constant and $\varepsilon_{0}$ is the permittivity of vacuum. Free charges can move under the influence of this electric field as if an external voltage was applied to the crystal. The idea behind the concept of pyroelectric spatial beam selftrapping is to light-induced the screening of this pyroelectric electric field by photorefractive effect. For efficient beam trapping to occur, light-induced field screening response time has to be shorter than response of field compensation by charge sorption on the polar surface of the crystal. Moreover, the amplitude of the pyroelectric field has to be large enough to form a deep waveguide by electro-optic effect. $\mathrm{LiNbO}_{3}$ possesses adequate characteristics to demonstrate this concept.

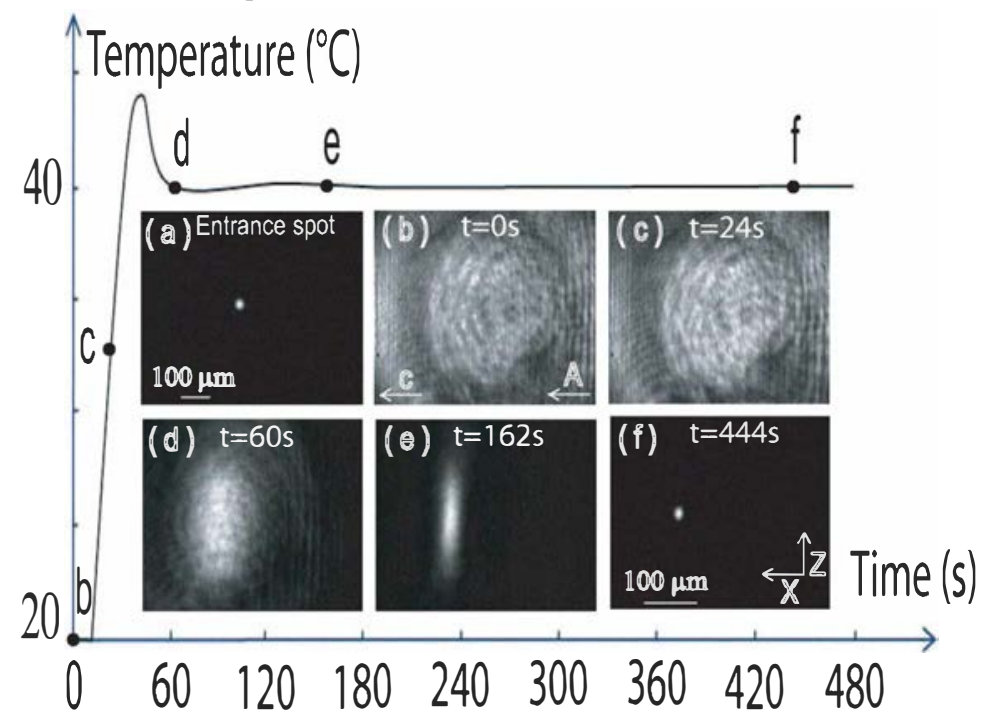

Fig. 1 Self-focusing dynamic in $20 \mathrm{~mm}$ long undoped stoichiometric lithium niobate $\left(\mathrm{LiNbO}_{3}\right)$ of an extraordinary polarized beam at $\lambda=532 \mathrm{~nm}$ under a temperature change $\Delta \mathrm{T}=20^{\circ} \mathrm{C}$. Images at the input face (a), at the output face at different instant (b-f) and crystal temperature evolution (curve). Parameters: input beam power: $80 \mu \mathrm{w}$, input beam size: $20 \mu \mathrm{m}$ (FWHM).

Experiments are performed in a $20 \mathrm{~mm}$ long undoped stoechiometric $\mathrm{LiNbO}_{3}$ sample. A moderate temperature change of 20 degrees is sufficient to trigger the self-trapping of a beam as shown by the dynamic depicted in figure 1. Similar results are obtained fort both ordinary and extraordinary light polarization in congruent or stoechiometric $\mathrm{LiNbO}_{3}$ samples. Bright spatial solitons can even be formed with proper experimental conditions.

A new kind of PR spatial soliton based on the pyroelectric effect is demonstrated. It provides a very simple way to induce waveguides or periodic index structures in ferroelectric crystals by temperature control. The demonstration performed in photonic grade $\mathrm{LiNbO}_{3}$ crystal brings even greater potential for practical applications.

\section{References}

[1] E. DelRe, B. Grosignani, and P. Di Porto, Spatial Solitons, Chapter "Photorefractive Spatial Solitons", S. Trillo and W. Torruellas eds. (Springer Verlag, Berlin Heidelberg, 2001).

[2] A. Savage, "Pyroelectricity and spontaneous polarization in $\mathrm{LiNbO}_{3}$, , J. Appl. Phys. 37, 3071 (1966).

[3] S. V. Yevdokimov, R. I. Shostak, and A. V. Yatsenko, "Anomalies in the pyroelectric properties of $\mathrm{LiNbO}_{3}$ crystals of the congruent composition," Phys. Sol. State. 49, 1957 (2007). 